\title{
Metacognitive Scaffolding in Reading Comprehension: Classroom Observations Reveal Strategies to Overcome Reading Obstacles of Engineering Students at QUEST, Nawabshah, Sindh, Pakistan
}

\author{
Mansoor Ahmed Channa ${ }^{1}$, Zaimuariffudin Shukri Nordin ${ }^{2} \&$ Abdul Malik Abassi ${ }^{3}$ \\ ${ }^{1}$ Quaid-e-Awam University of Engineering, Science, and Technology, Nawabshah, Pakistan \\ ${ }^{2}$ Faculty of Cognitive Sciences \& Human Development, University Malaysia Sarawak, Malaysia \\ ${ }^{3}$ Sindh Madressatul Islam University, Karachi, Pakistan \\ Correspondence: Mansoor Ahmed Channa, Quaid-e-Awam University of Engineering, Science, and Technology, \\ Nawabshah, Pakistan. E-mail: mansoor.english@yahoo.com
}

Received: December 3, 2017 Accepted: December 28, 2017 Online Published: February 4, 2018

doi:10.5539/ijel.v8n3p131 URL: http://doi.org/10.5539/ijel.v8n3p131

\begin{abstract}
This study aimed at investigating the development of reading comprehension of engineering students through metacognitive strategies and scaffolding. This study used 12 classroom observations in four engineering departments of one public university in Pakistan. The researcher observed 3 classes in each department at the time of read-aloud sessions. The class in each department was comprised on minimum 55 students and maximum 75 students. The researcher himself conducted all the 12 observations to maintain reliability without interfere of the complete teaching method. Teacher in each class was introduced by the observer and his aim to come in the first observation session. The observer sat at the back of every classroom and noted all instructional practices carefully on the field-notes based on teachers using metacognitive strategies to support students in terms of reading comprehension instructions. This study revealed the promising results based on metacognitive scaffolding and strategies as the most important tools for engineering students and language teachers to use for the development of reading and comprehension.
\end{abstract}

Keywords: reading comprehension, metacognition, reading strategies, scaffolding

\section{Introduction}

In Pakistan, the metacognition and cognition fields were ignored from undertaking research for developing the ability of students in language learning. This study would pave the way for researchers to develop their interest in language leaning through metacognitive strategies and would develop a trend of investigation to develop certain policies and planning for reading comprehension of engineering students. This research would be beneficial to propose propositions for designing teaching and learning materials of reading comprehension interconnecting metacognition and cognition in Pakistan. Some researchers including Flavell (1999), Bogdan (2000), and Metcalfe (2000) explained metacognition as the knowledge about the philosophy of thinking practices concerning the cognizance to reproduce the thought processes; thinking process is also used to create implications-related to the exercises on prior understanding. Further, Metcalfe, (2000) specified that metacognition can be considered as the regulatory system of thinking by using one's intellects; which can imperatively be used to control the thoughts, knowledge, and actions of a person (Weinert, 1987). This proves that metacognition can be related towards the awareness of one's individual thoughts and the control of one's personal thinking or dogmas.

Moreover, Flavell's $(1976,1979,1999)$ studies reported that metacognitive awareness denotes as the acquired knowledge which can support to control the cognitive processes and can be used to assess the understanding of thinking processes. Similarly, Brown (1987) asserted that meta-comprehension is considered as the most important aspect of metacognitive knowledge that enables student to understand a question clearly; however, regulation enables students to utilize that piece of knowledge to develop rational performance for comprehension purposes. In the same way, metacognitive awareness develops regulation effectively to utilize for enhancing the capability of performance (Brown, 1987). However, Veenman et al. (2006) stated that it is very difficult to distinguish between metacognitive and cognitive; both are considered as the two faces of one coin depending on each other to work 
together for functioning the thinking or mental performances of activities on reading comprehension. The most important three kinds of metacognition were identified by Cross \& Paris, (1988) that included as: (1) Declarative knowledge refers to the knowledge based on factors influencing human cognition, (2) Procedural knowledge is used to know by what means certain abilities function and in what manner these abilities or skills can be used, and (3) Conditional knowledge is used to know the information related to the strategies needed for solving certain tasks. Further, students can practice through the certain tasks involving individual cognitions as stated by (Efklides, \&Petkaki, 2005) for practicing a number of mental states including personal interest and a method of judgment concerning tasks dealing out for better outcomes. Therefore, Flavell, (1979) informed that knowledge and regulation are reciprocally interconnected under the umbrella of metacognition. However, Schraw, \& Dennison, (1994) presented Metacognitive Awareness Inventory (MAI) which indicated that the knowledge and regulation are strongly interconnected in cognition development and the results of Sperling et al. (2004) confirmed this theory and further informed that metacognitive awareness and regulation effect provided a method of selection of strategies to be used.

\subsection{Background of the Study}

In Pakistan, Federal Ministry of Education is responsible for certain affairs related to the education. Nurullah \& Naik (1951) exposed some drawbacks in the system that includes insufficiencies of the pedagogy, dearth of appropriate instructors, and low setup. The federal government helps to develop curriculum and finance for the research in the country. Sarwar et al. (2011) informed that textbooks ignore the curriculum covering the objectives of the teachers and students in the country and do not meet the standards of the world. Similarly, multinational companies in Pakistan prefer to recruit employees having sound knowledge of reading texts as they need to be capable of reading and comprehending agreements, contracts, bonds, deals, and give-and-take official messages through emails with seniors, managers, coworkers, and in their daily businesses (Sarwar et al., 2011). In Pakistan, English language is considered as an official language and is medium of instructions within schools, colleges and universities (Mansoor, 2005). Further, the curriculum of engineering education is in the process of developing at both official and private level of teaching and learning. English language is widely recognized as a foreign language in more than 100 countries of the world including Thailand, China, Japan, Brazil, and Europe along with other countries like Singapore, Pakistan, India, and Philippines teaching English as either second language or medium of instruction or official language (Crystal, 2003). Further, the Government of Pakistan has introduced text books for improving reading proficiency in all fields including engineering, science, and technology in all government funded engineering universities at graduate level to provide quality education introducing research under various scholarship programs across the country (Pakistan Ministry of Education, 2006).

In addition, there are different engineering programs at QUEST, Pakistan and English language centre supports engineering departments by providing knowledge in reading scientific and technical texts related to the fields to a greater extent. In Pakistan, English language is used as the medium of instruction in all institutions related to the education; this language is also considered as the official language in the country. Similarly, multinational companies in Pakistan prefer to recruit employees having sound knowledge of reading texts as they need to be capable of reading and comprehending agreements, contracts, bonds, deals, and give-and-take official messages through emails with seniors, managers, coworkers, and in their daily businesses. Wei (2005) considered reading as the most essential tool for developing educational and professional achievement. Wei (2005) further informed that students want to apprehend text-books, research articles in order to obtain knowledge to support academic studies. Aebersold \& Field (1997) asserted that reading is important in learning but most students are unable in reading texts effectively due to different reading problems. These problems include inappropriateness of the reading, the misapprehension of grammar, vocabulary problems, and poor background knowledge (Nuttall, 2000).

\section{Review of Literature}

The idea of metacognition was presented by Kluwe (1987) who asserted that thinker can easily identify about personal thought processes and others' thought as well in the one category; whereas, in other category, a thinker can attend personal thoughts and has the ability to change thinking related to the activity which is being called as the "executive processes" of metacognition. In addition, Hacker (1998) indicated the demarcation between cognitive and metacognitive tasks. Cognitive tasks can be used in retention of knowledge learned previously and interconnect with the existing tasks; whereas metacognitive tasks can be used in monitoring the tasks and directing the process of activities involving thinking to acquire more knowledge. Further, Hacker, (1998) reported that Metacognitive knowledge indicates the knowledge of a person; whereas metacognitive abilities refer about the tasks which are presently undertaken; metacognitive experiences involve affective state of a person or cognitive 
state of the students related to the activity. Afflerbach et al. (2008) informed the fact that cognitive aspect stresses on solving any problem during learning; while, metacognitive concentrates the process of solving any task or activity. Additionally, Veenman et al. (2006) stated that metacognition can be classified into two divergent features that include the knowledge of cognition that refers to the information related to the factors interacting in such a way that is used to affect the cognitive courses and generate outcomes; whereas the regulation of cognition (Flavell, 1979) refers to the information involving personal or independent learning and course of actions based on individual thoughts. Further, Channa, Yossatorn, \&Yossiri (2012) conducted qualitative study and investigated the perceptions of international students studying in medical and engineering departments and used strategies at the time of learning language in one university in Thailand. The findings suggested that the use of strategies do encourage students to boost up their performance in language learning. Similarly, other studies (Channa \& Nordin, 2014; Channa et al., 2015; Channa \& Nordin, 2015) revealed that the metacognition can progress the cognitive responsiveness and cognitive regulation of students' comprehension to find exact meaning of academic and professional texts. Similarly, Channa et al. (2013) investigated needs, wants, and problems in English of first year engineering students in QUEST, Pakistan. The study revealed that the reading ability of engineering undergraduates were at a low level. This main purpose of this research was to identify in what way first year engineering students apply metacognitive strategies and also identify the differences between these engineering students.

Research indicates that metacognitive scaffolding supports metacognitive activities and facilitates problem-solving processes. Only a small number of studies have investigated the lack of metacognitive scaffolding in the context of reading comprehension of engineering students. For instance, Ge \& Land (2003) found that students who received metacognitive scaffolding performed significantly better than those who did not receive. The influence of the first language (L1) on the acquired language (L2) is a common research topic in linguistics: A larger linguistic distance between L1 and L2 is believed to hamper any potential language transfer (the application of knowledge in the mother tongue to second languages) and to make it more difficult to differentiate between different sounds and words. Linguistic studies typically analyze the effect of linguistic distance employing small samples or case studies. Further, Whitebread et al. (2005) conducted research and indicated that most research in the field of metacognition in reading comprehension is done involving early ages respondents of either primary or secondary schools; very few investigations are made for college or university students to know their perceptions. The findings suggest that even our youngest children are capable of considerable independence in their learning; despite the fact that particular pedagogical techniques and approaches need to be developed, many of these are well-established and researched, and can be shown to be effective in fostering independent learning abilities. Conversely, metacognition can be developed with the experiences of students; this knowledge mostly is found among older students than that of their younger counterparts (Flavell, 1979; Flavell, 1981).

Moreover, the main issues of engineering students were based on low, average, and high reading proficiency levels of students. Their inability to read is affected due to the factors that include intellectual, psychological, physical, socio-economic, gender difference, urban and rural area, age, government and private schooling background, learning environment, and teaching methodology (Rehman, 2005; Mansoor, 2005). Despite the importance of metacognition to students' learning, little is known about how engineering students engage in metacognitive behaviors. If syllabus or curriculum is developed to support reading comprehension through metacognition in engineering, students would be engaged through metacognitive behaviors and contextual factors would impact students when they would study on their own. To understand the baseline level of metacognitive use, specific pedagogical approaches can be developed targeting weak metacognitive skills and continue to build stronger metacognitive skills for reading comprehension. There is a need in understanding of how different contextual factors impact metacognitive scaffolding in reading comprehension to emphasize the positive factors while minimizing the negative factors in curriculum development in engineering education (Steif et al., 2010; Streveler et al., 2008). The use of metacognition in reading can be hampered by the fact that current methodological approaches for studying metacognition are not appropriate; therefore, the appropriate methods to study metacognition in reading comprehension need to be developed to know what students are doing metacognitively in order to support their reading abilities. The teachers in the engineering fields train students as they can use their gained knowledge in their studies to solve problems, make developments, and propose new technologies (Steif et al., 2010). Conversely, there are evidences that students have been graduating from undergraduate institutes having strong misconceptions about primary areas, for instance physics, thermodynamics, electricity, statics, and materials (Steif et al., 2010; Streveler et al., 2008). Further, Phang \& Yusof (2013) explained that engineering education research needs in setting up good series of research to achieve considerable results for developing quality education in engineering and producing quality graduates for overcoming the present 
challenges in the fields. Similarly, Phang \& Yusof (2013) asserted for the improvement of engineering education and engineers for the solution of novel problems involving several disciplines; they need to have the skills to use new information in order to control over their obstacles.

\section{Research Method}

Data were gathered through classroom observations of four engineering departments at QUEST (A public university) in Pakistan. Classroom observations were conducted in the read-aloud lessons of communication skills subject in the four engineering departments at first year engineering classrooms to investigate the metacognitive strategies used in reading comprehension. The main aim of classroom observations was to focus on teachers' instruction on reading to engineering students involving metacognitive strategies. The amount of time to each classroom observation was fixed and 3 hours were allocated to each reading lesson in each department. There were total 12 observations and 3 observations per classroom were spent on the reading activities. The class in each department was comprised on minimum 55 students and maximum 75 students. Following (Strauss, \& Corbin 1990) as a complete observer, the researcher himself conducted all the 12 observations to maintain reliability without interfering the complete teaching method. Teacher in each class introduced the observer and his aim to come in the first observation session. The observer sat at the back of every classroom and noted all instructional practices carefully on field-notes including teachers using metacognitive strategies, support to the students, and reading comprehension instructions.

\section{Findings of the Study}

The engineering students of four departments at QUEST, Nawabshah came to know about what potential metacognitive strategies were noted as beneficial to develop their comprehension in reading academic as well as general texts and their level of reading growth. Conversely, differences were noted during classroom observation by the researchers when each and every metacognitive strategy among all students was used. Similarly, the data gathered through observations was analyzed and the following main themes were generated for the interpretation of the results.

\begin{tabular}{ll}
\hline Level One Code & Level Two Codes \\
\hline Reading Comprehension & 1. Text Scanning \\
& 2. Text Skimming \\
\hline Metacognitive Strategies & 1. Brainstorming \\
& 2. Selecting difficult words \\
& 3. Using prior knowledge \\
& 4. Using dictionary \\
& 5. Summarizing \\
& 6. Paraphrasing \\
& 7. Questioning \\
\hline Scaffolding & 1. Teachers'support \\
& 2. Peers' support \\
\hline
\end{tabular}

\subsection{Classroom Observation Report: Reading Comprehension}

Reading comprehension was occurred in the read-aloud sessions of four engineering department through different strategies following academic text. Scanning and skimming were noted as the reading strategies and were found reading themes from field notes of classroom observations. These were also certified by teachers and students interviews.

\subsubsection{Text Scanning}

It was found in the observation that teachers asked students to use scanning strategy in order to find important information from the text. Two of these observations showed that teachers asked students to use scanning whereas; one more observation indicated that students themselves focused on scanning strategy to find out required data quickly. These observations showed:

"....students should use scanning strategy to look titles of the passages....and to get the information quickly...." [Observation Four]

“...scanning strategy helps students to raise their reading speed with quick information....” [Observation Seven]

“...before reading in detail....I use scanning strategy by looking at the text instead of reading word by word.... and find titles or sub-titles...." [Observation Nine] 


\subsubsection{Text Skimming}

It was reported through field notes that they used text skimming while reading activities. Two of these observation revealed that they practiced reading text through skimming using eyes for looking quick information. Two of these observations showed:

“...skimming helps us to get quick knowledge of the text. Our teacher has insisted us to get the birds' eye view of the text." [Observation One]

"Students should use skimming technique to get information quickly. They should read text with their eyes...." [Observation Eleven]

\subsection{Classroom Observation Report: Metacognitive Strategies}

It was found in the observation that some of these teachers used metacognitive Strategies in the read-aloud sessions of four engineering classrooms following academic text. The strategies were found from gathered data through field-notes included brainstorming, selecting difficult words, using prior knowledge, using dictionary, summarizing, paraphrasing, and questioning-answering strategy. These strategies were also verified through teachers and students interviews.

\subsubsection{Brainstorming}

The use of brainstorming strategy was reported through data gathered in the observations and noted in the field notes. Both teachers and students practiced using brainstorming as the activity and tried to draw graphs and mind maps by thinking about what the text would be in the reading and where the important data should be laid down in the text.More than half of the observations revealed that they practiced reading text through brainstorming and thinking strategy. Some of these observation examples are presented:

"I ask my students to practice on brainstorming while reading academic texts...thinking and making image of the text in mind would be useful for students to comprehend..." [Observation Two]

“....we use thinking and brainstorming about text in reading activities. Brainstorming would help us to know the difficult parts of the texts...our teachers arrange activities in class....." [Observation Five]

“...it is difficult for predicting text with our thoughts... and forming our concept through brainstorming.....But we do practice on thinking and brainstorming to create images of the text." [Observation Nine]

"....we should read text and make images through thinking and brainstorming strategy to link text with our thoughts in mind..." [Observation Eight]

Interestingly, one of these observations informed that brainstorming is necessary to make mental images for headings and subheadings. One of these observations revealed:

“....thinking is the second name of brainstorming or cognition....students should practice for finding important data from text. Brainstorms would help students to form imageries about texts...” [Observation Twelve]

\subsubsection{Selecting Difficult Words}

The selection of difficult words was reported through data gathered in the observations in which most of observations clarified that readers should select difficult words to practice and to memorize for future and present use to understand the meaning of the text. The field-notes on observations revealed:

"I have been teaching my students to select difficult words and phrases.... and memorize all those for increasing vocabulary. I think difficult or unknown words stop reading speed or decrease comprehension ...." [Observation Three]

"......we select difficult words and memorize for future practice. If we would not find and remember all those difficult words.... we lose our reading level." [Observation Eight]

"I teach my students to remember difficult words... when they perform reading activities. If they remember these words in time...they would be benefited forever at any stage. [Observation Ten]

“...we always select all difficult vocabulary from text reading and do remember for future comprehension ..." [Observation Eleven]

\subsubsection{Using Prior Knowledge}

Using prior knowledge is the third theme of metacognitive strategy category as reported in the class observation through recorded field notes. Most of teachers guided their students to use their past experiences and prior knowledge with that of reading comprehension activity to understand exact meaning of the texts. Some examples 
of observations are presented:

“....using prior knowledge would be helpful to interconnect present knowledge with that of past experiences to analyze written text....” [Observation Three]

"....we can use prior information to connect with the present activity. Prior knowledge increases speed in reading and comprehension...." [Observation Seven]

"....if readers have poor background knowledge.... they cannot read well and would not understand the meaning of paragraphs...." [Observation Five]

Interestingly, one of these observations revealed that background knowledge supports students to recollect their previous memories and connect with the reading passages. One of these Observations showed:

“.....prior knowledge can support students to recall their past knowledge and to use with the activities in class. Students can evaluate them through this strategy and can develop their comprehension...." [Observation Ten]

\subsubsection{Using Dictionary}

It was found through classroom observation that less than half of the observations asserted to use dictionary whereas most of observations reported that use of dictionary is not beneficial for students during activities. These observations suggested that students should use dictionary after activity. During activity, students should apply through guesses for the meaning of the texts. Three of the Observation noted:

"...the dictionary is beneficial to know the meaning.... and to verify thoughts about the text." [Observation Two]

"...the use of a dictionary is very important to enhance vocabulary.... and help us to find correct meaning of the words...." [Observation Six]

"We should use dictionary after the completion of reading tasks. We should avoid using dictionary during reading activity....this would waste our time and we could not complete our task in time......" [Observation Five]

\subsubsection{Summarizing}

It came under the focus of observations that three of the teachers guided their students to read text and summarize in their own words. These teachers indicated that they asked students to make summary of the text in order to judge the ability of students. Conversely one of these observations reported that they did not use this strategy due to difficult terms and confused parts of the text. Three of these Observations revealed:

"...when students complete reading activity....they should be asked to summarize the text in their own words." [Observation Three]

“....we can reread the text for at least three times and summarize it to judge our knowledge and understanding of the text." [Observation Nine]

"....summarizing is important....that would enable us to read independently and comprehend written text...." [Observation Eleven]

"We do not use this strategy [Summarizing] if difficult terms are used with unfamiliar sentences...." [Observation Five]

\subsubsection{Paraphrasing}

It was observed through classroom observations that less than half of the Observations used paraphrasing in reading lessons. Teachers asked students to read articles and understand the meaning of the text. Only two teachers asked their students to evaluate their abilities through paraphrasing task. However, most of teachers did not give paraphrasing tasks to their students with the view that their students would not explain or paraphrase in their own words as they lack proper practice in this strategy. Two of these observations revealed:

“....paraphrasing activity would be beneficial for students to evaluate their abilities....” [Observation Seven]

“......we should enlist all the main ideas from text while reading...and paraphrase the paragraph to judge our reading performance." [Observation Three]

\subsubsection{Questioning}

Most of the observations reported that students should be asked questions to find answers from the texts. This practice would support them to see text carefully for searching suitable answers from the passages. Most of teachers asked questions before, during, and after reading tasks. Some of these observations reported:

“.....we should ask questions from our students before, during, and after reading activity. This strategy would enable them to pay attention in reading and would increase their reading interest...." [Observation Six] 
"...our teachers ask questions sometimes in the beginning of reading task and sometimes after the end of activity to judge our reading ability." [Observation Two]

“....we should ask questions when we complete our reading tasks to check our comprehension and to find difficult parts of the text...." [Observation Eight]

\subsection{Classroom Observation Report: Scaffolding}

In classroom observation, it came under the focus of observation that most of teachers helped their students in developing reading comprehension. The field-notes and data gathered through observations clearly indicated that teachers provided temporary support to their students until they could practice independently. Similarly, some teachers asked students to help their peers in completing reading activities. The observer observed that peers' help along with their teachers' support, students performed better as compared to those who could not receive support or those who could receive limited help in doing reading comprehension tasks.

\subsubsection{Teachers' Support}

Most of the observations reported that teachers' support can develop the knowledge of students. In result, students can independently practice on reading comprehension activities. Teachers provide temporary help and students get permanent knowledge and develop their speed in reading. The field-notes reveal information that teachers motivate their students and enhance their interest towards reading comprehension. Some of the examples of these observations are presented:

“....teachers' support can teach us the art of reading independently. If teachers would not provide help....we cannot develop our comprehension." [Observation Eight]

"Our teachers help us to complete our reading activities.... they provide us knowledge. If our teachers would not give help....we would not learn new ways of learning and practicing independently...." [Observation Three]

"I help my students in reading and guide them...to me teachers can develop the knowledge of their students through reading strategies..." [Observation Ten]

"....if we would support our students....students would practice without fear and with interest. If we would not guide....students would not participate in activities and would escape from..." [Observation Twelve]

\subsubsection{Peer's Support}

It was found through the field-notes on observations that peer support is important for students to develop their reading comprehension. Students can support their mates freely and can ask anything without any fear which they feel from their teachers. These observations reported that students receive support from their peers can perform better than that of a friend who has not receive support. Some observations reveal:

“.... when peers help their friends in class, they work without fear. We help each other in reading activities and solve problem together....." [Observation Two]

“....support of classmates can develop interest in reading....if we would not help them today...they would not help us tomorrow..." [Observation Five]

"Peer support helps us to work in collaboration in class activities. This [peer support] develop the sense of teamwork among students..." [Observation Ten]

"I ask my students to work in group on reading tasks and guide them to support each other when they find any difficulty." [Observation Twelve]

\section{Discussion, Conclusion, and Recommendations}

This study is closely related with the Chumpavan's (2000) research which indicated that students while reading faced great difficulties in reading and comprehension. They also had the problems in prior knowledge which lacked in understanding texts correctly and used dictionary to apprehend the texts. Similarly, the results of this research reported that most of students lack background information and face greater problems or barriers while reading texts. They failed in recalling their background experiences or prior knowledge when they read passages. Similarly, these students could not complete their reading tasks in time. In short, the most of students failed to make correct guesses of the texts and could not identify the exact meaning of the texts. Moreover, the engineering respondents used metacognitive Strategies at QUEST, Pakistan and the way these respondents adopted to use in reading text. This present research indicated that the engineering students were completely attentive and knew about their reading comprehension strengths and weaknesses to regulate their thinking abilities at the time of reading texts of the passages. The results acquired from class observations of read-aloud activities data suggested that the engineering respondents used their metacognitive strategies in order to make 
their comprehension easy to apprehend the meaning of reading passages. The results of this present research are reliable and consistent as compared with the results of earlier studies which asserted that the readers always used metacognitive strategies to help their reading comprehension to be enhanced (Chumpavan, 2000) and make students to know their reading proficiency and practice for its improvement. This research has shown the significance in terms of strategies (metacognition) for engineering students in their reading practice and the processes of comprehension. These findings are regarded as the consistent with the study of Chumpavan (2000) which revealed the metacognitive strategies to be used by Thai students studying at Illinois State University for more than two years in USA; they were highly expert in reading comprehension. The study focused on metacognitive strategies and her findings revealed that the participants applied strategies for planning, monitoring, and evaluating their reading texts, their abilities, and their comprehension proficiency.

To conclude, this present research approves the claims made in the past research in terms of the strategies identified and used by the participants. This present study also confirms that using metacognitive strategies means to improve the comprehension levels of the texts by the engineering students. The informants of this study reported that they used different metacognitive strategies in order to develop their understanding. Therefore, they sorted out the strategies including scanning to take the bird's eye view of the text, mental images to make overall picture of the text, selecting main ideas, topic sentences, and important words or phrases to clarify their understanding and build new knowledge. Further, these respondents also used prior knowledge for getting the proper meaning and interconnecting previous knowledge with that of their present knowledge. They also guessed from contextual clues when they did not understand the texts apart from using dictionaries in case of difficult words. This study was conducted to explore metacognitive scaffolding and strategy use in reading comprehension. The information obtained from the class observations represents a basic step for language planners when they create and improve appropriate courses. Therefore, recommendations for further research are presented as follows:

1) It is recommended that for further studies, comparative qualitative study should be conducted involving two different universities in order to collect data regarding perceptions towards metacognitive strategies in developing reading in other fields, such as technical education.

2) This study examined the reading problems of engineering students using metacognitive strategies. To obtain more motivating data, further research should investigate other aspects including age and reading proficiency, task-based activities, and students' involvement in reading based on their selection of topics and subjects.

3 ) It is recommended that future work should focus on determining the level of metacognition. Low level metacognitive knowledge lacks connection to explicit conceptual justification; while, high level metacognitive knowledge binds discussions straightforwardly to conceptual reasons.

4) It is recommended that future work would guide all those who involve in designing syllabus, curriculum, and policy makers to get guideline from this research in order to develop reading materials for the students in Pakistan.

\section{References}

Aebersold, J. A., \& Field, M. L. (1997). From reader to reading teacher. Cambridge: Cambridge University Press.

Alyousef, H. S. (2005). Teaching reading comprehension to ESL/EFL learners. The Reading Matrix, 5(2), 143-154.

American College Testing, ACT. (2006). Reading between the lines: What the ACT reveals about college readiness in reading. Retrieved from http://www.act.org/research/policymakers/pdf/reading_summary.pdf

Anderson, V. (1991). Training to foster active reading strategies in reading-disabled adolescents. Paper presented at the annual meeting of the American Educational Research Association, Chicago.

Block, E. (1986). The comprehension strategies of second language readers. TESOL Quarterly, 20(3), 463-494. https://doi.org/10.2307/3586295

Boulware-Gooden, R., Carreker, S., Thornhill, A., \& Joshi, R. (2007). Instruction of metacognitive strategies enhances reading comprehension and vocabulary achievement of third-grade students. Reading Teacher, 61(1), 70-77. https://doi.org/10.1598/RT.61.1.7

Cain, K., Oakhill, J., \& Bryant, P. (2004). Children's reading comprehension ability: concurrent prediction by working memory, verbal ability, and component skills. Journal of Educational Psychology, 96, 31-42. http://dx.doi.org/10.1037/0022-0663.96.1.31

Camahalan, F. M. G. (2006). Effects of a metacognitive reading program on the reading achievement and 
metacognitive strategies of students with cases of dyslexia. Reading Improvement, 43(1), 77-93.

Chen, H. C. (2002). A preliminary study of Chinese EFL learners' difficulties in vocabulary learning and remedial learning strategies. Papers selected from the 17th conference of TVES Education, 81-91, Taipei: Crane.

Chinwonno, A. (2001). A comparison of Thai and English reading comprehension strategies of pre-service teachers in Thailand. $\mathrm{PhD}$ dissertation, Ohio University.

Chumpavan, S. (2000). A qualitative investigation of metacognitive strategies used by Thai students in second language academic reading. SLLT, 9, 62-77.

Cohen, A. D. (1998). Strategies in learning and using a second language. NY: Addison Wesley Longman.

Dhieb-Henia, N. (2003). Evaluating the effectiveness of metacognitive strategy training for reading research articles in an ESP context. English for Specific Purposes, 22, 387-417. https://doi.org/10.1016/S0889-4906(03)00017-6

Eskey, D. E. (2005). Reading in a second language. In E. Hinkel (Ed.), Handbook of Research in second language teaching and learning (pp. 563-580), Mahwah, NJ: Lawrence Erlbaum.

Fauzan, N. (2003). The effects of metacognitive strategies on reading comprehension: a quantitative synthesis and the empirical investigation. Durham theses, Durham University. Retrieved from http://etheses.dur.ac.uk/1086/

Fisher, D., \& Frey, N. (2003).Writing instruction for struggling adolescent readers: A gradual release model. Journal of Adolescent and Adult Literacy, 46, 396-405.

Flemming, L. E. (1997). Reading for thinking (2nd ed.). Boston: Houghton Mifflin.

Gough, P. B. (1972). One second of reading. In J. F. Kavanagh \& I. G. Mattingly (Eds.), Language by ear and by eye (pp. 331-358). Cambridge, MA: MIT Press.

Hammadou, J. (1991). Interrelationship among prior knowledge, inference, and language proficiency in foreign language reading. The Modern Language Journal, 75(1), 27-38. https://doi.org/10.1111/j.1540-4781.1991.tb01080.x

Kelly, M., Moore, D. W., \& Tuck, B. F. (1994). Reciprocal teaching in a regular primary classroom. The Journal of Educational Research, 88(1), 53-61. https://doi.org/10.1080/00220671.1994.9944834

Lapp, D., Fisher, D., \& Grant, M. (2008). You can read this text-I'll show you how: Interactive comprehension instruction. Journal of Adolescent \& Adult Literacy, 51(5), 372-383. https://doi.org/10.1598/JAAL.51.5.1

Leddy C. (2008). The Alarming state of reading in America. Writer, 121(5).

Levitov, D. D. (2010). Reading as a 21 st-century skill cannot be taken lightly, School Library.

Li, S., \& Munby, H. (1996). Metacognitive strategies in second language academic reading: A qualitative $\begin{array}{llll}\text { investigation. English for Specific } & \text { Purposes, } & 15(3), & 199-216 .\end{array}$ https://doi.org/10.1016/0889-4906(96)00004-X

Nuttall, C. (1996). Teaching reading skills in a foreign language (New edition). Oxford, UK: Heinemann.

Ra-Ngubtook, W. (1993). A comparison of the effectiveness of "direct" and "embedded" metacognitive learning strategy training models in English reading comprehension for upper secondary school students. Unpublished Master's thesis, Chulalongkorn University, Bangkok, Thailand.

Shanahan, T., Callison, K., Carriere, C., Duke, N. K., Pearson, P. D., Schatschneider, C., \& Torgesen, J. (2010). Improving reading comprehension in kindergarten through 3rd grade: A practice guide. Washington, DC: National Center for Education Evaluation and Regional Assistance, Institute of Education Sciences, US Department Of Education. Retrieved from $\mathrm{http} / / /$ ies.ed.gov/ncee/wwc/pdf/practice_guides/readingcomp_pg_092810.pdf

Smith, F. (2004). Understanding reading: A psycholinguistic analysis of reading and learning (6th ed.). Mahwah, NJ: Lawrence Erlbaum.

Snowling, M. (2002). Dyslexia: Individual and developmental differences, Learning and Teaching Reading. British Journal of Educational Psychology, Monograph Series II, the British Psychological Society.

Stanovich, K. E. (1980). Toward an interactive-compensatory model of individual differences in the development of reading fluency. Reading Research Quarterly, 16, 32-71. https://doi.org/10.2307/747348 
Stewart M. T. (2002). Best practice: Insights on literacy instruction from an elementary classroom. Newark, DE: International Reading Association; Chicago: National Reading Conference.

Taverner, D. (1990). Reading within and beyond the classroom. Milton Keynes, Philadelphia: Open University Press.

Thiede, K. W., Griffin, T. D., Wiley, J., \& Redford, J. S. (2009). Metacognitive monitoring during and after reading. In D. J. Hacker, J. Dunlosky, \& A. C. Graesser (Eds.), Handbook of Metacognition and Self-Regulated Learning (pp. 85-106). New York: Routledge.

Urquhart, A. H., \& Weir, C. J. (1998). Reading in a second language: Process product and practice. New York: Addison Wesley Longman.

Wilkinson, I. A. G., \& Son, E. H. (2011). A dialogic turn in research on learning and teaching to comprehend. In M. L. Kamil, P. B. Rosenthal, P. D. Pearson, \& R. Barr (Eds.), Handbook of reading research: Volume IV (pp. 359-387). New York: Routledge.

\section{Copyrights}

Copyright for this article is retained by the author(s), with first publication rights granted to the journal.

This is an open-access article distributed under the terms and conditions of the Creative Commons Attribution license (http://creativecommons.org/licenses/by/4.0/). 